\title{
Physicians' Appraisal and Response to Early Evidence on Cardiovascular Risk Associated with Rosiglitazone: Knowledge Translation in Clinical Practice
}

Garielle E. Brown, Adriane M. Lewin MSc, Michael A. De Souza BSc, Alun L. Edwards MD, William A. Ghali MD MPH, Doreen M. Rabi MD MSc

\begin{abstract}
About the Author
Garielle Brown (right) is a student in the Department of Science at the University of Calgary, in Calgary, Alberta, and is completing her final year in the Bachelor of Science, Natural Sciences program. Michael A. De Souza, Alun L. Edwards, William A. Ghali, and Doreen M. Rabi are members of the Department of Medicine, University of Calgary. Adriane M. Lewin, Alun L. Edwards, William A. Ghali, and Doreen M. Rabi are with the Calgary Institute of Population and Public Health, University of Calgary. Alun L. Edwards, William A. Ghali, MD, and Doreen M. Rabi are with the Libin Cardiovascular Institute of Alberta. Correspondence may be directed to Doreen.Rabi@AlbertaHealthServices.ca.
\end{abstract}

\begin{abstract}
Summary
In 2007, a high-profile meta-analysis raised concerns about the safety of rosiglitazone, a thenpopular oral hypoglycemic agent. In this study, the authors describe how physicians accessed, evaluated, and applied this information clinically. Their findings showed that although a highly publicized meta-analysis raised concerns among physicians, meta-analyses can be challenging to interpret. Efforts are needed to improve the understanding of this methodology to aid physicians in translating results into practice.
\end{abstract}

\section{Résumé}

En 2007, une métaanalyse qui a fait grand bruit a soulevé des préoccupations quant à l'innocuité de la rosiglitazone, antidiabétique oral prescrit assez couramment à cette époque. Les auteurs de l'étude présentée ici examinent les modalités d'accès aux données issues de cette métaanalyse, et leur évaluation et mise en application par les médecins en pratique clinique. Leurs constatations illustrent que même si une métaanalyse soulève des questions avec un grand retentissement dans la communauté médicale, l'interprétation de ses résultats demeure complexe. Les auteurs concluent à la nécessité de mieux faire connaître cette technique d'analyse aux médecins pour leur faciliter la tâche de mettre en application ses résultats.

$\mathrm{T}$ There are many pharmacological options for the treatment of type 2 diabetes mellitus, and until late 2007, thiazolidinediones (TZDs) were a popular therapeutic choice. ${ }^{1}$ By acting as an agonist to the peroxisome proliferator-activated receptor gamma (PPAR- $\gamma)$, a receptor that influences lipid metabolism and glucose homeostasis, TZDs decrease insulin resistance, decrease hepatic gluconeogenesis, and increase peripheral glucose uptake. ${ }^{2}$ In addition to these metabolic benefits, TZDs were found to decrease inflammatory markers and improve vascular function. ${ }^{3-5}$ Collectively, these apparent benefits generated excitement about the potential that these agents might have to favourably modify the natural history of diabetes and vascular disease, and they were widely prescribed. However, with this extensive use, evidence began to emerge that TZDs were also associated with serious negative effects, including edema, weight gain, increased bone resorption in 
women, and increased risk of congestive heart failure. ${ }^{6,7}$ In May of 2007, a meta-analysis and systematic review by Nissen and Wolski looking at the association of rosiglitazone (the most commonly prescribed TZD at that time) with myocardial infarction (MI) and mortality was published in the New England Journal of Medicine. ${ }^{8}$ A statistically significant increase in the risk of MI was reported for rosiglitazone when compared to other oral hypoglycemic agents or placebo; a non-significant increase in the risk of death for patients in the rosiglitazone group was also noted.

In the 3 years after the publication of this review, additional reviews and observational studies raised concerns regarding the cardiovascular risk associated with the use of rosiglitazone. ${ }^{9-14}$ As this evidence evolved, the safety of rosiglitazone underwent review by regulatory bodies in both North America and Europe. ${ }^{15,16}$ In the lengthy interval between the publication of the Nissen and Wolski review and the re-evaluation of rosiglitazone safety by the United States Food and Drug Administration (FDA) in the summer of 2010, physicians were left to make their own appraisal regarding the relative benefits and safety of treatment with rosiglitazone.

Critical appraisal of new evidence is an essential process in the practice of evidence-based medicine (EBM) ${ }^{17}$ Meta-analysis has, however, been identified as a potential challenge for practitioners of EBM as many physicians are less familiar with the statistical methodology or how best to appraise this evidence. ${ }^{18,19}$ The objective of this study was to survey practising physicians in a Canadian province to determine their appraisal of the available evidence relevant to the safety of rosiglitazone (particularly the Nissen and Wolski meta-analysis), and examine practices on the use of this specific agent for the treatment of type 2 diabetes mellitus.

\section{Methods}

\section{Study Design}

Self-administered survey packages were mailed to 448 physicians across Alberta. The College of Physicians and Surgeons of Alberta (CPSA) database was used to draw a complete listing of all practising non-pediatric endocrinology specialists $(n=34)$ and general internal medicine specialists $(n=213)$ in the province of Alberta, along with a random sample of 201 general practitioners (GPs) stratified by location to approximate the population distribution of the province. Participants were excluded from the sample if they were not involved in the care of patients with diabetes and/or did not prescribe oral hypoglycemic agents for the management of type 2 diabetes. The survey package included a cover letter describing the survey and an indication that there were no investigator conflicts of interest; a letter of support from a local practice leader; a two-page self-administered survey; and a response card. Recipients were requested to complete the questionnaire and return it in a provided postage paid envelope. Those who did not wish to participate were asked to return a postage paid response card that indicated their decision not to participate, along with the reason for declining. Surveys were mailed out in April 2008 following ethics approval from the Conjoint Health Research Ethics Review Board at the University of Calgary.

\section{Questionnaire}

The questionnaire consisted of 27 closed-ended questions with additional space provided for comments. The first item ("Are you involved in the care of patients with diabetes?") and third item ("Do you prescribe oral hypoglycemic agents for the management of type 2 diabetes?”) functioned as exclusion criteria. The remaining items fell broadly into three categories: awareness of the Nissen and Wolski meta-analysis and/or the ensuing media coverage, sources of information on rosiglitazone safety, and how this information was interpreted and applied in clinical practice. Prior to circulation, pilot testing of the survey was undertaken with a small sample of physicians $(n=6)$ to verify clarity of the survey and to ensure receptivity of providers to its content.

\section{Survey Methodology}

Multiple strategies were employed to increase response rates, including a letter of support from local practice leaders, a clear indication that there were no investigator conflicts of interest, and two reminder letters. ${ }^{20}$ Recognizing that many of the surveyed physicians may not be involved in the care of patients with diabetes, we requested in our letter of invitation that these physicians or physicians who did not wish to participate return a non-responders card.

\section{Sample Size Considerations}

We purposefully chose to survey all internists, all adult endocrinologists, and a sample of more than 200 GPs to achieve a targeted population of 448 physicians. Anticipating a response rate of only one in three physicians (because low response rates are typical in survey studies targeting physicians), our study sample would produce $95 \%$ confidence intervals no bigger than $\pm 5 \%$ around reported proportions.

\section{Statistical Analysis}

The analysis involved descriptive statistics. All variables were categorical and were reported as proportions. Differences in 


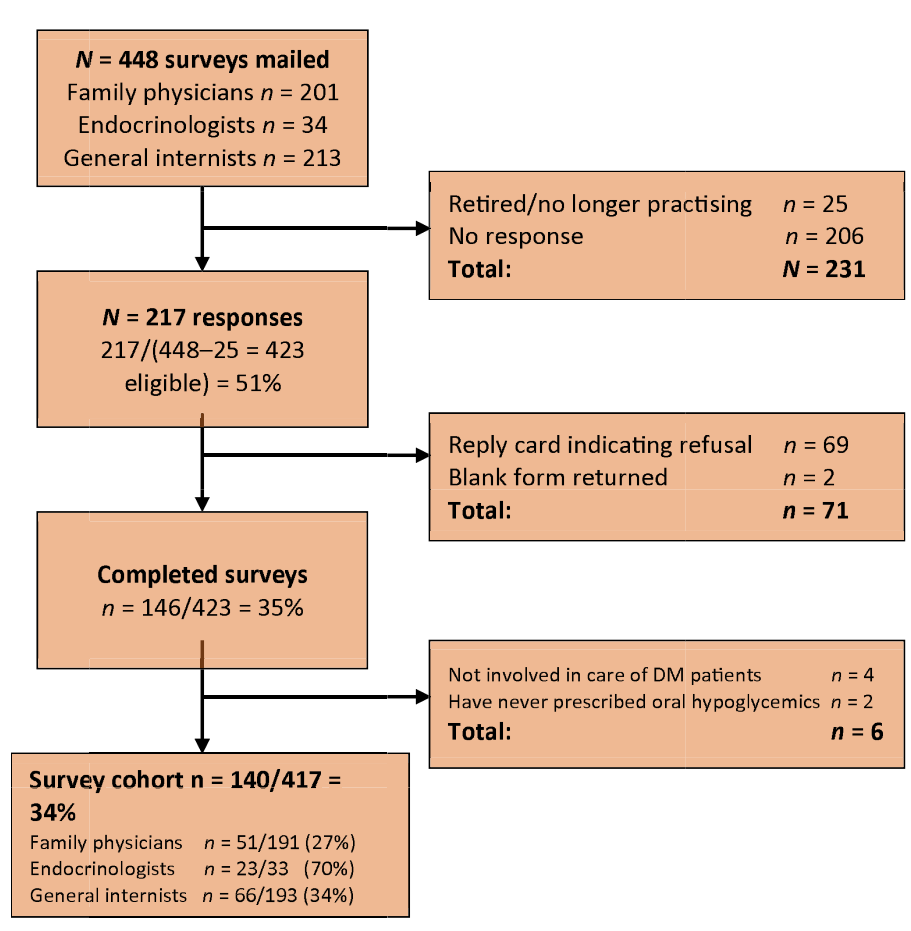

Figure 1. Physician survey study cohort and reasons for exclusion. proportions were assessed using chi-square or Fisher's exact test as appropriate.

\section{Results}

\section{Study Population}

A total of 448 surveys were mailed to physicians practising in Alberta. We received responses from 217 physicians, providing us with an initial response rate of $51 \%$. Of the 217 responses, 69 physicians returned the response card indicating that they had received the survey but did not wish to participate in the study and 25 others were no longer practising. After exclusions due to eligibility and refusal, the final response rate was $34 \%$ (140/417) (Figure 1), including 27\% of eligible GPs (51/191), $70 \%$ of eligible endocrinologists (23/33), and $34 \%$ of eligible internists (66/193). Of the 140 respondents to the survey, 36\% $(n=51)$ were GPs, $16 \%(n=23)$ were endocrinologists, and $47 \%(n=66)$ were internists.

Table 1 outlines the characteristics of the study participants. A greater proportion of internists were male, 77\% $(51 / 66)$ versus $52 \%(12 / 23)$ in endocrinology and $63 \%(32 / 51)$ in general practice. Specialists (endocrinologists and internists) were older and more likely to hold a university appointment than were GPs. Of all participants, 64\% (89/140) reported some formal training in epidemiology or critical appraisal, though this varied across specialty, with GPs reporting the least training at $53 \%(27 / 51)$ and internists the most at $71 \%(47 / 66)$.

Table 1. Demographic Characteristics of Survey Respondents

\begin{tabular}{|c|c|c|c|c|c|}
\hline Gene & $\begin{array}{l}\text { eral Practitioners } \\
n=51(\%)\end{array}$ & $\begin{array}{l}\text { Endocrinologists } \\
\qquad n=23(\%)\end{array}$ & $\begin{array}{l}\text { General internists } \\
\quad n=66(\%)\end{array}$ & $\begin{array}{l}\text { Overall } \\
n=140\end{array}$ & $p$ Value \\
\hline Male & $32(62.8)$ & $12(52.2)$ & $51(77.3)$ & $95(67.9)$ & .05 \\
\hline Age group & & & & & $.51 *$ \\
\hline $25-34 y$ & $10(19.6)$ & $2(8.7)$ & $6(9.1)$ & $18(12.9)$ & \\
\hline $35-49 y$ & $18(35.2)$ & $12(52.2)$ & $32(48.5)$ & $62(44.3)$ & \\
\hline $50-64$ y & $20(39.2)$ & $9(39.1)$ & $24(36.4)$ & $53(37.9)$ & \\
\hline $65+y$ & $3(5.9)$ & 0 & $4(6.1)$ & $7(5.0)$ & \\
\hline Hold a university appointment & $12(23.5)$ & $21(91.3)$ & $47(71.2)$ & $80(57.1)$ & $<.01$ \\
\hline Number of years in practice & & & & & $.11^{*}$ \\
\hline$<5 y$ & $10(19.6)$ & $4(17.4)$ & $9(13.6)$ & $23(16.4)$ & \\
\hline 5 to $<10 y$ & $3(5.9)$ & $6(26.1)$ & $15(22.7)$ & $24(17.1)$ & \\
\hline $10-15 y$ & $6(11.8)$ & $4(17.4)$ & $11(16.7)$ & $21(15.0)$ & \\
\hline$>15 y$ & $32(62.8)$ & $9(39.1)$ & $31(47.0)$ & $71(51.4)$ & \\
\hline Practice setting & & & & & .13 \\
\hline Solo & $7(13.7)$ & $6(26.1)$ & $18(27.3)$ & $31(22.1)$ & \\
\hline Group & $39(76.5)$ & $12(52.2)$ & $36(54.6)$ & $87(62.1)$ & \\
\hline Other & $5(9.8)$ & $5(21.7)$ & $12(18.2)$ & $22(15.7)$ & \\
\hline $\begin{array}{l}\text { Formal training in epidemiology } \\
\text { or critical appraisal }\end{array}$ & $27(52.9)$ & $15(65.2)$ & $47(71.2)$ & $89(63.6)$ & .12 \\
\hline
\end{tabular}

*Denotes Fisher's exact test. 


\section{Evaluation of Rosiglitazone Evidence and Appraisal of Safety}

At the time of the survey, rosiglitazone was thought to be acceptably safe by the majority of internists and GPs, $77 \%$ $(51 / 66)$ and $80 \%(41 / 51)$, respectively, but by significantly fewer endocrinologists $(57 \%$ or $13 / 23)(p=.05)$. While over a third of surveyed endocrinologists $(39 \%, 9 / 23)$ felt rosiglitazone was unsafe, significantly fewer GPs $(16 \%, 8 / 51)$ and internists $(15 \%$ $10 / 66)$ appraised rosiglitazone as unsafe $(p=.05)$. When asked to appraise the quality of the Nissen and Wolski meta-analysis, $70 \%$ of survey respondents who read the original article (41/59) found it to be a "moderate-to-good" article, with no significant differences between physician groups.

A greater proportion of endocrinologists $(65 \%, 15 / 23)$ and internists $(44 \%, 29 / 66)$ found the Nissen and Wolski article helpful in providing information about rosiglitazone, compared with only $6 \%(3 / 51)$ of GPs. GPs, however, reported that they found pharmaceutical representatives informative, and used them as a primary information resource, significantly more relative to endocrinologists or internists (16\% versus $0 \%$ and $5 \%$, respectively, $p=.03$ ). Medical editorials and other medical press that summarized the available information were used equally across physician groups, and all groups found colleagues to be helpful in providing information.

While all three groups reported receiving a similar number of safety concerns from their patients, endocrinologists and internists felt most prepared to deal with these concerns, with $75 \%(15 / 20)$ and $71 \%(32 / 45)$, respectively, saying they were adequately prepared. Unlike the specialist physicians, the majority of GPs felt unprepared to deal with patient concerns and questions, with only $30 \%$ (13/43) saying they felt adequately prepared.

\section{Application of Information in Clinical Practice}

Of the 140 respondents, 96 (69\%) reported that they had patients who requested to discontinue the use of rosiglitazone following the publication of the Nissen and Wolski article and the ensuing media attention, with no significant differences between physician groups; these were patients who had been taking rosiglitazone prior to the release of the article. Sixty percent (84/140) of the respondent physicians themselves chose to discontinue the use of rosiglitazone in their patients. Although rosiglitazone treatment was discontinued for many patients, $43 \%$ of GPs (22/51), $42 \%$ of internists (28/66), and $23 \%$ of endocrinologists (5/23) said that they would continue prescribing this medication to appropriate patients who were not currently taking the drug.

For patients currently using rosiglitazone at the time of the survey, the majority of endocrinologists $(87 \%, 20 / 23)$ and only slightly fewer GPs $(63 \%, 32 / 51)$ and internists $(70 \%, 46 / 66)$ said they would consider continuing to use the drug on a case-bycase basis.

\section{Discussion}

The primary objective of this survey was to determine how physicians appraised the safety of rosiglitazone following the publication of the Nissen and Wolski meta-analysis. We determined that the appraisal of safety differed based on specialty, with GPs and internists considering rosiglitazone to be safer than endocrinologists did. We also sought to document practices regarding rosiglitazone, and our survey revealed that despite differences in the appraisal of safety, the final practice patterns with respect to rosiglitazone were remarkably similar across physician groups. This finding is intriguing and suggests marked discrepancy between views on safety and actions in practice. However, this finding may also speak to the very challenging process of clinical decision making, particularly as it pertains to a complex clinical condition such as type 2 diabetes mellitus. Physicians caring for patients with diabetes needed to weigh this evidence of possible harm associated with rosiglitazone against the risks and barriers associated with switching to, or introducing, a new therapy (intolerance, compromise in glycemic control, non-adherence, financial burden to the patient). The weights associated with each competing risk differ between patients, and in this formulation we can see that the safety appraisal of rosiglitazone may not be the only factor influencing rosiglitazone practices.

Practices regarding rosiglitazone continue to evolve, and the results of this survey reveal some interesting issues with respect to the interpretation and application of new knowledge to clinical practice. First, information sources used by physicians to educate themselves about rosiglitazone differed by specialty: GPs were more inclined to use pharmaceutical representatives, compared with internists or endocrinologists who reported the academic literature as their most-used resource. All physicians considered colleagues a helpful resource.

Secondly, the study by Nissen and Wolski was a difficult piece of evidence to process rapidly and integrate into practice, as was evidenced by the fact that nearly $70 \%$ of GPs felt ill prepared to deal with patient concerns. Internists' and endocrinologists' relatively increased level in comfort in managing patient concerns may be related to diabetes care constituting a proportionally greater amount of their clinical practice; therefore, they may have been more familiar with the evidence base that contributed the meta-analysis. It is also 
possible that GPs were less comfortable with interpreting this form of evidence. Well-conducted meta-analyses are considered a high level of clinical evidence, ${ }^{21,22}$ but there is evidence to suggest that meta-analyses are not well used by physicians. In the present study, only $42 \%$ of respondents had personally read the Nissen and Wolski review, the remaining having learned about the article and its findings from alternative resources. De Vito and colleagues ${ }^{18}$ found that despite recognizing their importance, less than $20 \%$ of a sample of Italian physicians read meta-analyses on a regular basis and only half of those physicians ultimately applied their findings to practice. Barriers to the translation of meta-analysis to practice include a lack of familiarity with the statistical methods and a lack of experience in appraising this form of evidence.

At the time this survey was conducted, the use of rosiglitazone was on the decline. Studies examining dispensing patterns of rosiglitazone in both Canada and the United States revealed a significant temporal association between the release of the Nissen and Wolski article and the decline in new prescriptions for rosiglitazone and commensurate increase in the use of other available oral hypoglycemic agents. ${ }^{23-25}$ Given the temporal association, it has been posited that the Nissen and Wolski article was the principal piece of evidence driving this change. It must, however, be recognized that coincident with the publication of the Nissen and Wolski meta-analysis was the publication of other observational studies that demonstrated that use of TZDs were associated with an increased risk of fractures ${ }^{6,26}$ and hospital admission for congestive heart failure. ${ }^{9,10,27}$ Our study specifically examined the impact of the Nissen and Wolski article on physician appraisal and practices regarding rosiglitazone, and found that the Nissen and Wolski meta-analysis was indeed a major factor contributing to the change in rosiglitazone use.

Our study does have limitations. Our study surveyed physicians in only one region of Canada and produced a response rate of only $34 \%$. However, this is a relatively high response rate for a physician survey, and it captured three highly relevant disciplines that provide diabetes care. Furthermore, we suspect that the views of physicians in the jurisdiction studied are likely to be representative of physicians in other jurisdictions.

Our survey findings suggest that the Nissen and Wolski meta-analysis did raise concerns about safety among physicians providing diabetes care. While the appraisal of the safety of rosiglitazone was not consistent across patient groups, depending on whether patients were currently using rosiglitazone or not, there was a notable change in rosiglitazone practice following this meta-analysis. At a more general level, this study provides further evidence that physicians use multiple resources to inform them when evidence that might alter practice emerges. Lastly, meta-analysis can be a challenging form of evidence to interpret, and efforts to improve the understanding of this methodology among practising physicians may increase physician confidence in translating meta-analysis results to patients and practice.

\section{Acknowledgements}

We would like to thank Drs. Julie McKeen, Peter Grundy, and Susan Kinnear for their assistance with validity assessment of the survey, and Dr. Jacques Romney for his support as a practice leader.

Doreen Rabi is funded by a Population Health Investigator award from Alberta Innovates - Health Solutions. William Ghali is funded by a Senior Scholar award from Alberta Innovates -Health Solutions and holds a Canada Research chair in health services research.

\section{References}

1. Alexander GC, Sehgal NL, Moloney RM, et al. National trends in treatment of type 2 diabetes mellitus, 1994-2007. Arch Intern Med 2008;168(19):2088-94.

2. Moore DD. 'No, really, how do they work?' Genes Dev 2005;19(4):413-4.

3. Martens FM, Visseren FL, Lemay J, et al. Metabolic and additional vascular effects of thiazolidinediones. Drugs 2002;62(10):1463-80.

4. Sidhu JS, Cowan D, Kaski JC. The effects of rosiglitazone, a peroxisome proliferator-activated receptor-gamma agonist, on markers of endothelial cell activation, C-reactive protein, and fibrinogen levels in non-diabetic coronary artery disease patients. J Am Coll Cardiol 2003;42(10):1757-63.

5. Sidhu JS, Cowan D, Kaski JC. Effects of rosiglitazone on endothelial function in men with coronary artery disease without diabetes mellitus. Am J Cardiol 2004;94(2):151-6.

6. Schwartz AV, Sellmeyer DE, Vittinghoff E, et al. Thiazolidinedione use and bone loss in older diabetic adults. J Clin Endocrinol Metab 2006;91(9):3349-54.

7. Dormandy JA, Charbonnel B, Eckland DJ, et al. Secondary prevention of macrovascular events in patients with type 2 diabetes in the PROactive Study (PROspective pioglitAzone Clinical Trial In macroVascular Events). a randomised controlled trial. Lancet 2005;366(9493):1279-89.

8. Nissen SE, Wolski K. Effect of rosiglitazone on the risk of myocardial infarction and death from cardiovascular causes. N Engl J Med 2007;356(24):2457-71.

9. Juurlink DN, Gomes T, Lipscombe LL, et al. Adverse cardiovascular events during treatment with pioglitazone and rosiglitazone: population based cohort study. BMJ 2009;339:b2942.

10. Lipscombe LL, Gomes T, Levesque LE, et al. Thiazolidinediones and cardiovascular outcomes in older patients with diabetes. JAMA 2007;298(22):2634-43.

11. Richter B, Bandeira-Echtler E, Bergerhoff K, et al. Rosiglitazone for type 2 diabetes mellitus. Cochrane Database Syst Rev 2007;(3):CD006063.

12. Singh S, Loke YK, Furberg CD. Long-term risk of cardiovascular events with rosiglitazone: a meta-analysis. JAMA 2007;298(10):1189-95.

13. Starner CI, Schafer JA, Heaton AH, et al. Rosiglitazone and pioglitazone utilization from January 2007 through May 2008 associated with five riskwarning events. J Manag Care Pharm 2008;14(6):523-31.

14. Tzoulaki I, Molokhia M, Curcin V, et al. Risk of cardiovascular disease and all cause mortality among patients with type 2 diabetes prescribed oral 
antidiabetes drugs: retrospective cohort study using UK general practice research database. BMJ 2009;339:b4731.

15. European Medicines Agency. European Medicines Agency recommends suspension of Avandia, Avandamet and Avaglim. Anti-diabetes medication to be taken off the market. London, United Kingdom: The Agency; 2010;

http://www.ema.europa.eu/docs/en_GB/document_library/Press_release/2010/09/WC5000 96996.pdf.

16. Woodcock J, Sharfstein JM, Hamburg M. Regulatory action on rosiglitazone by the U.S. Food and Drug Administration. N Engl J Med 2010;363(16):1489-91.

17. Sackett DL, Haynes RB, Guyatt GH, et al. Clinical Epidemiology: A Basic Science for Clinical Medicine, 2nd edition. Boston (MA): Little, Brown and Company; 1991.

18. De Vito C, Nobile CG, Furnari G, et al. Physicians' knowledge, attitudes and professional use of RCTs and meta-analyses: a cross-sectional survey. Eur J Public Health 2009;19(3):297-302.

19. Berwick DM, Fineberg HV, Weinstein MC. When doctors meet numbers. Am J Med 1981;71(6):991-8.

20. Edwards P, Roberts I, Clarke M, et al. Methods to increase response rates to postal questionnaires. Cochrane Database Syst Rev 2007;(2):MR000008.

21. Atkins D, Best D, Briss PA, et al. Grading quality of evidence and strength of recommendations. BMJ 2004;328(7454):1490.

22. Atkins D, Eccles M, Flottorp S, et al. Systems for grading the quality of evidence and the strength of recommendations I: critical appraisal of existing approaches. The GRADE Working Group. BMC Health Serv Res 2004;4(1):38.

23. Levitan D. Rosiglitazone: one year later. Thorofare (NJ): SLACK Inc., 2008; http://www.endocrinetoday.com/view.aspx?rid=29105.

24. Morrow RL, Carney G, Wright JM, et al. Impact of rosiglitazone meta-analysis on use of glucose-lowering medications. Open Med 2010;4(1):E50-9.

25. Shah BR, Juurlink DN, Austin PC, et al. New use of rosiglitazone decreased following publication of a meta-analysis suggesting harm. Diabet Med 2008;25(7):871-4.

26. Bilik D, McEwen LN, Brown MB, et al. Thiazolidinediones and fractures: evidence from translating research into action for diabetes. J Clin Endocrinol Metab 2010;95(10):4560-5.

27. Lago RM, Singh PP, Nesto RW. Congestive heart failure and cardiovascular death in patients with prediabetes and type 2 diabetes given thiazolidinediones: a meta-analysis of randomised clinical trials. Lancet 2007;370(9593):1129-36.

\section{Your input matters.}

HELP SHAPE THE FUTURE OF YOUR PROFESSION.

Votre opinion compte. CONTRIBUEZ A FAÇONNER L'AVENIR DE VOTRE PROFESSION.

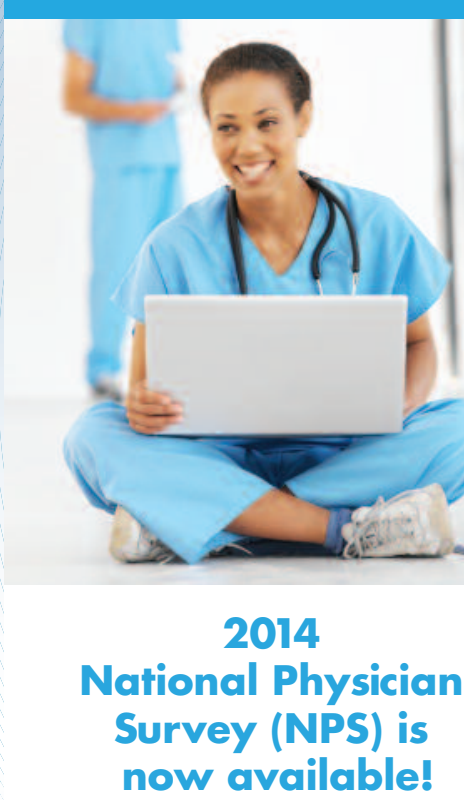

Contribute to a valuable data resource for all.

Participate and you could win $\$ 1,000$ and may be eligible to earn CPD credits.

www.national physiciansurvey.ca

@npscanada

\section{Le Sondage national} des médecins 2014 (SNM) est maintenant disponible!

Contribuez à cette importante source de données.

Participez pour courir la chance de gagner $1000 \$$ et obtenir des crédits de DPC.

www.sondagenationaldesmedecins.ca

@snmcanada

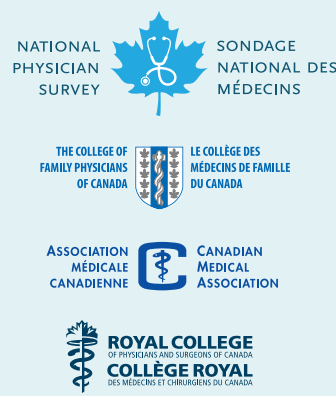

